\title{
Research on college English teaching under DEMATEL Environment Yuanyuan Zhang
}

Zhengzhou university of industrial technology.Henan.China

\begin{abstract}
This paper is based on the meaning of multiple DEMATEL teaching mode as the breakthrough point, by means of the analysis model, the cognitive learning model and the construction of cognitive model with behavioral learning aid to discuss the implementation strategy of college English teaching under the DEMATEL environment, in order to enhance the validity of college English teaching and provide a useful reference. Research on classroom activities mainly adopts the observation method, which is focused on the expansion of the external factors that can have influence on teacher's talk, student's participation, as well as the type of interaction,etc.The college English teaching activities under the DEMATEL environment must fully mobilize the positive factors, so as to improve the students' classroom participation effectively, which can improve the effect of English teaching at the same time.
\end{abstract}

\section{Introduction}

Classroom interaction refers to the mutual communication between teachers and students, or among students in the classroom. Research on classroom interaction mainly has two kinds of different perspectives in foreign countries, namely: research on classroom activities and research the acquire of the second language. Research on classroom activities mainly adopts the observation method, which is focused on the expansion of the external factors that can have influence on teacher's talk, student's participation, as well as the type of interaction,etc.

\section{Fuzzy DEMATEL}

Decision Making Trial and Evaluation Laboratory (DEMATEL) was first introduced at Battelle Memorial Institute of Geneva Research Center . This method was applied in relation to complicated problems of the world such as famine, energy, environmental protection and etc in that time. DEMATEL is one the multi criteria decision making instruments and has the ability to convert the qualitative designs to the $\square$ quantitative analysis . The aim of DEMATEL is to convert the relation between criterions, causal dimensions from a complex system to an understandable structural model of that system.

\section{The DEMATEL`s steps:}

We specify evaluation factors according to expert committee's opinion and research background. We determine each factor influences on whole system, according to expert's opinion. To do so, we use discussed wordy expressions in table1. After that we used CFC method (Equations 1 to 6) to convert the fuzzy results into crisp value.

$$
\begin{aligned}
& X L_{i j}^{k}=\left(L_{i j}^{k}-\min _{1 \leq i \leq k} L_{i j}^{k}\right) / \Delta_{\min }^{\max } \\
& X M_{i j}^{k}=\left(M_{i j}^{k}-\min _{1 \leq i \leq k} L_{i j}^{k}\right) / \Delta_{\min }^{\max } \\
& X r_{i j}^{k}=\left(r_{i j}^{k}-\min _{1 \leq i \leq k} L_{i j}^{k}\right) / \Delta_{\min }^{\max } \\
& \Delta_{\min }^{\max }=\max r_{i j}^{k}-\min L_{i j}^{k} \\
& X s_{i j}^{k}=\frac{X m_{i j}^{k}}{\left(1+X m_{i j}^{k}-X l_{i j}^{k}\right.}
\end{aligned}
$$




$$
X r s_{i j}^{k}=\frac{X r_{i j}^{k}}{\left(1+X r_{i j}^{k}-X m_{i j}^{k}\right.}
$$

\section{The Meaning of Multiple DEMATEL Teaching Mode}

Among the "multiple interaction", the multiple factors refer to all the teaching elements related to learning, interaction, which can be including teaching staff, such as teachers and students; teaching elements, such as books and learning materials, etc.; teaching condition as well as teaching environment. While "DEMATEL" refers to make full use of elements, so as to learn about teaching elements related to the interaction, which can help to encourage students to take initiative part in the study with a series of teaching and learning activities, in an effort to achieve high teaching and learning quality efficiently. The type of teaching and learning activities should be an organic whole as interaction between various elements of teaching, which should be the dialectical unity of subject and object, therefore, the goal of teaching can be generated dynamically.

The so-called "multiple DEMATEL" teaching mode, is a kind of activities that are under the environment of information technology, the teaching activities as a process of interaction of multiple communication and dynamic optimization, through the DEMATEL teaching mode, it can make full use of various teaching elements related to learning, adjusting the contact between the elements, so as to mobilize the initiative of students and promote students to carry out the learning activities.In some degree, it is a new teaching form that the formation is in harmonious interaction with omni-directional and multi-level degree, in an effort to improve teaching effects.

College English DEMATEL teaching activities refer to the activities that teachers and students are the main subjects, who take part in English teaching activities not only in class, but also out of the class, with some extracurricular the activities under the three-dimensional environment or under the virtual network space "between teachers and students or among the students". In this process, the main role of the teacher is to guide, coordinate and promote students' foreign language learning; on the other hand, students can complete learning language knowledge and make use of the rules to internalize the language behavior during the process of case study through practice, exploration and interaction, so as to improve students learning abilities as well as practical abilities.

\section{Cognitive Learning Model}

Cognitive learning theory is a remarkable effect theory after Thorndike's behaviorism theory. The cognitive learning theory is originated from the Gestalt school. The basic view of cognitive learning theory is that the process of learning can stimulate the result of the interaction between the learner cognition as well as the response to the external environment, which puts emphasis on learning, memory and learning, so as to acquire new knowledge. Learning is not directly transmitted from the external environment to the learners' translation memory, which is based on the combination of the existing knowledge and experience with the external environment and the construction of the acquired information.As shown in fig1.

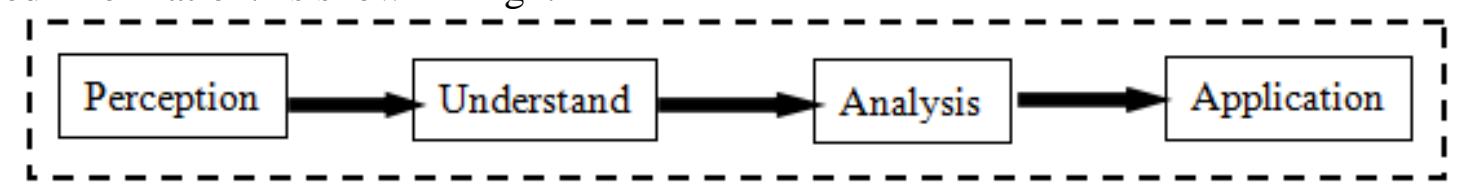

Fig. 1 Teaching Mode based on the cognitive learning theory

First of all, the learners should have some ideas about the teaching contents, then the teachers should guide learners understand language points through the analysis of the learner and situation exercises, so as to make use of the application of language and language behavior. In this way, the learners can form the ability to construct their own language knowledge. So the cognitive learning theory can answer the key question of human learning, namely the relationship between cognition and emotion. 


\section{The Construction of Cognitive Models}

Analysis of research on classroom interaction need more in-depth understanding about the internal factors of learners, in addition to the impact of the external factors on the environment, the task type of the interaction, as well as the elements of input or output of language from the linguistic perspective. This paper compares several traditional learning modes together, taking the constructivism and cognitive science as the theoretical basis, establishing the construction of the neurocognitive model, in order to more clearly display the internal mechanism of the second language learners. The process of learning has been an important researching part for educational psychology. Study on the acquisition of the second language is gained with the development of its theoretical basis. From behaviorism to information processing theory (especially the symbolic computation that is based on objectivism school), which meaning is completely determined by the object itself. While the understanding of things is exciting which is also a process of receiving information. Therefore, the traditional cognitive processing model can be summarized as follows:

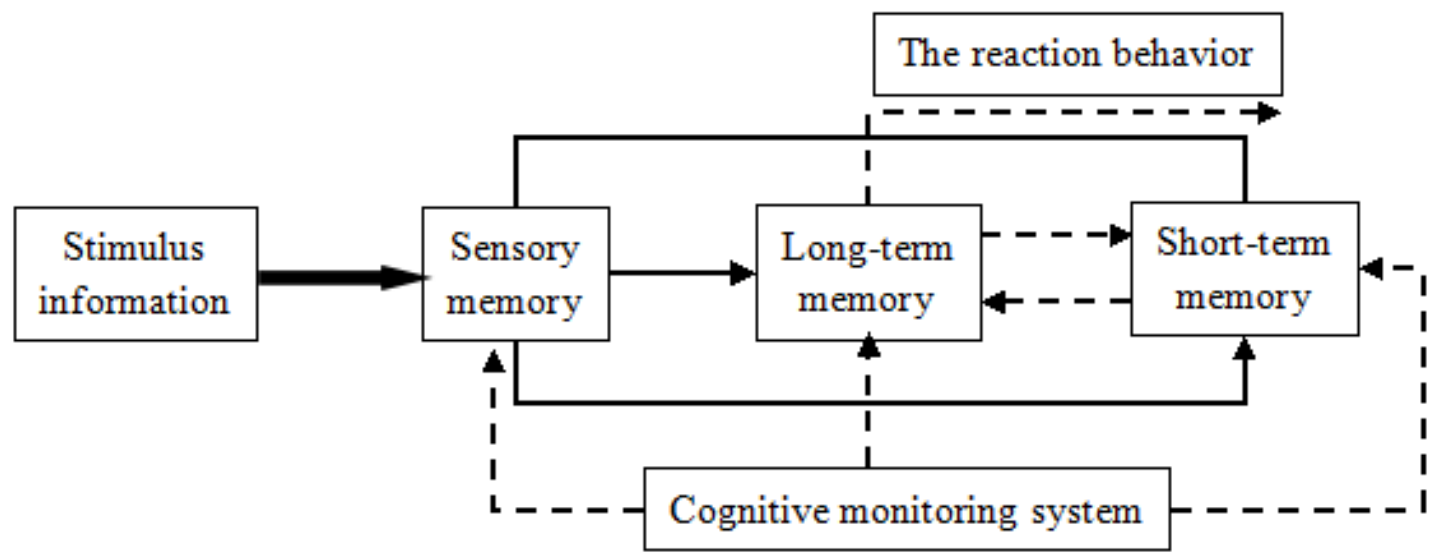

Fig. 2 .The Traditional Cognitive Processing Model

The traditional mode takes learning as a simple inputting process that knowledge is learned from the outside to the inside of the learners, which is also a one-way process of memory. According to cognitive learning model that is based on the traditional teaching method and the shortcomings of the constructivism, it proposed a more scientific view. Constructivism holds that the core of learning activities is the interaction process of the learners which should be an external input. Learners can study through assimilation and and accommodation within the mind during the process of interaction with the external input.As shown in fig 2.

According to the cognitive theory, people who study can set up and create new neural connections with neural networks in the brain, assimilation the can be produced by new synapses; at the same time, the adjustment of the old connection can be completed with the abandoned synapses disappeared. The completion of this process is accompanied by the main body of learning, namely, "people" can learn from the outside to get new information. While the way to get information is the interaction with the outside world, as for the specific foreign language teaching, it is essential to have classroom interaction. Therefore, the constructivism neurocognitive model within the internal process based on language acquisition is as follows:

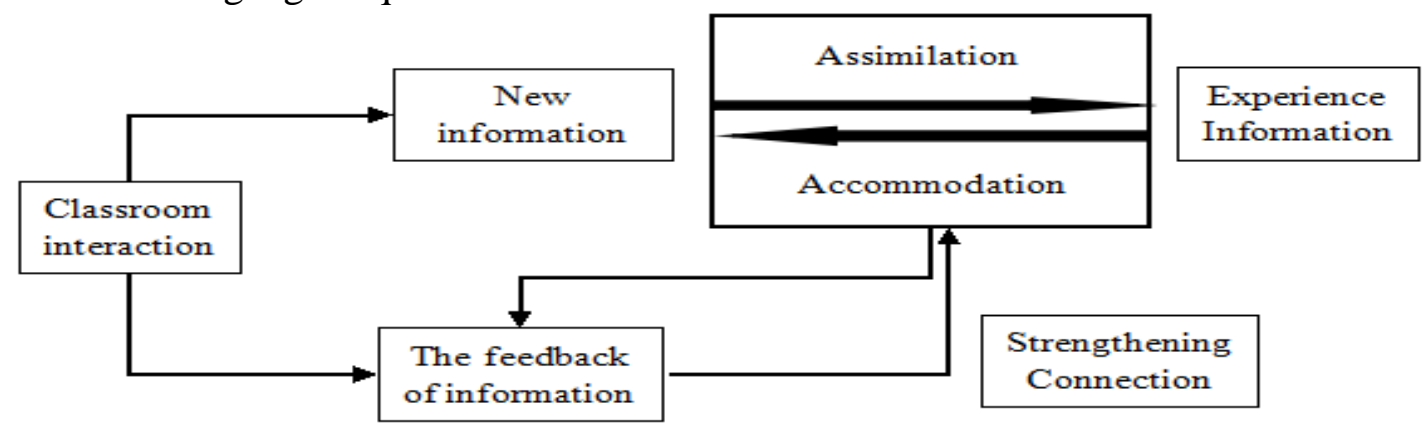

Fig.3.The neurocognitive model of Constructivism 
As it is shown in Fig.3. through classroom interaction, learners acquire the input of new information so that the neurons can generate new synapses in the brain neural network, or the new neurons are activated. The establishment of new neuronal connections with the repeated activation or strong stimulation of the neurons can remember new information combined with the experience information. And the neurons can easily be activated again. It is the realization of assimilation process. At the same time, the old connections are adjusted in order to adapt to the new formation of synaptic connection, the abandoned units gradually lost their functions, finally the new information turn into the experience information, which is the process of accommodation. After the two processes are finished, people realize the acquisition.

\section{Conclusion}

Compared with the traditional teaching model, multiple DEMATEL teaching mode has many characteristics, such as the teaching methods are blended; the teaching environment is open; the relationship between teachers and students is equal; the teaching activities are multiple and diverse; the teaching effect is effective;the teaching management is efficient and so on.These features have advantages over the other teaching modes that cannot be matched, such as, it can enhance students' oral communication opportunity and create a relaxed learning environment; it can improve students' learning autonomy and cooperation ability; it also can promote the comprehensive development of language skills and cultivate the consciousness of lifelong learning and so on.

\section{Reference}

[1]Skinner. Verbal Behavior.1957. New York: Appleton-century Crofts, Inc.. pp56-58.

[2]Slavin, R. E. 1995. Cooperative Learning: Theory, Research and Practice. Boston, MA: Allyn and Bacon. pp43.

[3]Spolsky, B. 1989. Conditions for second language learning: Introduction to a general theory [M]. Oxford: Oxford University Press. pp166.

[4]Warschauer, M. \& Healey, D. 1998. Computers and language learning: An overview. Language Teaching, pp57-71.

[5]Wenden, A. 1986. Helping language learner think about their learning. ELT journal. pp3-12.

[6] Wu, H,H., Computer software DEMATEL practice and exploration of teaching reform. The exam week, 8,1,11-21(2009). 